\title{
RELIABILITY TESTING OF SELF-CARE OF HEART FAILURE INDEX V6.2 CHINESE INSTRUMENT AMONG HEART FAILURE PATIENTS
}

\section{Adam Jian Yang Tan', Priyalatha Govindasamy', Nor Firdous Mohamed', Norashikin Md} Sari2, Nur Amani Ahmad Tajuddin², Aizai Azan Abdul Rahim³

1. Sultan Idris Education University, Malaysia

2. University of Malaya, Malaysia

3. National Heart Institute, Malaysia

Correspondence: d072383@siswa.upsi.edu.my

\section{ABSTRACT}

\section{OBJECTIVE:}

Self-Care of Heart Failure Index ( $\mathrm{SCHFI)}$ 6.2 Chinese is an instrument used to assess the ability of self-care behaviour among heart failure patients. It has been validated in Taiwan; however it is yet to be validated in Malaysia. As a multi-ethnic country, Chinese language has been one of the major languages in Malaysia. Therefore, this study was conducted to examine the reliability of Self-Care of Heart Failure Index (SCHFI) v6.2 Chinese among Malaysian population.

\section{DESIGN:}

A successive independent sample design was used throughout a 4-months data collection period.

\section{SETTING:}

Eighty heart failure patients from University of Malaya Medical Centre and National Heart Institute were recruited through purposive sampling. The two hospitals were chosen because they have specialized heart clinics that eased the data collection. The out-patients were screened by the cardiologists for their eligibility to participate in this study.

\section{MEASURES:}

The samples were administered with SCHFI v6.2 Chinese. The item endorsement index, internal consistency and item-total correlation of SCHFI v6.2 Chinese was examined.

\section{RESULTS:}

The maintenance subscale of SCHFI showed a low internal consistency (Cronbach a $=.52$ ) while the management and confidence subscales showed an acceptable internal consistency (Cronbach $a=.67$ and .90 respectively).

\section{CONCLUSION:}

SCHFI v6.2 Chinese is a reliable instrument to be used to be used among Malaysian population.

\section{KEYWORDS}

heart failure, reliability, self-care 
INTRODUCTION

According to World Health Organization, cardiovascular diseases (CVDs) is the number one cause of death globally.[1] In 2016, there were approximately 17.9 million of people died from CVDs. This makes up the $31 \%$ of the global death. In Malaysia, heart disease is an important cause of morbidity and mortality. Due to the ageing of Malaysia population, the burden of coronary heart disease is estimated to multiply in the future.[2] In fact, about $6 \%$ to $10 \%$ of all acute medical hospitalization are due to heart failure in Malaysia.[3]

In Malaysia, there are $8 \%$ of heart failure readmission within 30 days of discharge.[4] According to Star2.com, Malaysia is still lack of patients' support outside hospital setting.[5] There is also limited data on psychometric characteristics of self-care among local Malaysian heart failure population.[6] In fact, it is important for the healthcare professional to understand the ability of the heart failure patient to perform a proper self-care. Therefore, the healthcare professionals need a standardized tool to evaluate the heart failure patients in performing self-care.

The commonly used tools to assess the self-care of heart failure patients are European Heart Failure Self-Care Behaviour Scale (EHFSCBS) and Self-Care of Heart Failure Index (SCHFI). EHFSCBS is a brief and practical measure to assess the self-care behavior while SCHFI provide information about the deficiency area in self-care.[7] Through the assessment of self-care, the healthcare professional can have a better understanding on the patients and hence improve the quality of treatment.

The original Self-Care of Heart Failure Index (SCHFI) v6.2 was developed in English language by Riegel et al.[8] However, Malaysia has a multi-ethnics population with diverse languages. The average age of heart failure patients in Malaysia is 58 years, which may face language barriers. [910] During doctor-patient communication, language has become a challenge. One of the populations that is affected is Chinese population. This study focused on the Chinese version of SCHFl because Chinese population was the second major population with heart failure in Malaysia.[11]

Previous study has been conducted in Taiwan using SelfCare of Heart Failure Index (SCHFI) v6.2 Chinese, showing that Cronbach's alpha of self-care maintenance, self-care management and self-care confidence subscale were $.635, .716$ and .860 respectively.[12] Besides, confirmatory factor analysis supported the model fit of SCHFI v6.2 and this is similar to the previous version of SCHFI v4.[8] In Malaysia, SCHFI v6.2 Chinese has yet been validated. Therefore, this study was aimed to determine the reliability of Self-Care of Heart Failure Index (SCHFI) v6.2 Chinese among patients with heart failure admitted to University of Malaya Medical Centre (UMMC) and National Heart Institute (IJN), Malaysia.

\section{METHODS}

\section{RESEARCH DESIGN AND SAMPLE}

A successive independent sample design was conducted in this study over four months. A total of 80 participants from University of Malaya Medical Centre (UMMC) and National Heart Institute (IJN), Malaysia were recruited by purposive sampling. The inclusion criteria of participants are:

I. heart failure patients with New York Heart Association (NYHA) functional classification I, II or III

II. patients with reduced left ventricular ejection fraction of $\leq 55 \%$ or mild diastolic dysfunction,

III. participants should also be able to understand Chinese language.

Whereas the exclusion criteria are patients with cognitive impairment, for example Alzheimer's disease, Parkinson's disease and dementia.

\section{INSTRUMENTS}

The Patient version - Self-Care of Heart Failure Index (SCHFI) was first developed in English version by Riegel et al.[13] The instrument used in this study was translated into Chinese version by Yu et al.[7] The SCHFI v6.2 Chinese consists of 18 items. The instrument consists of 3 domains, which are maintenance ( 6 items), management ( 6 items) and selfconfidence ( 6 items). The first self-care process is maintenance, which is defined as the medical adherence and engagement of healthy behaviors. Secondly, the management process involves patients' response to the symptoms. Lastly, the self-care confidence scale represents the confidence level of patients in performing self-care.[14] The instrument utilizes a 4-point Likert scale ranged from 1 (never or rarely) to 4 (always or daily).

\section{PROCEDURES}

The ethical approval for this study was sought from the UMMC Medical Research Ethics Committee (MREC) (Ethic No.: 2019618-7526) and IJN Research Ethics Committee (IJNREC) (Ethic No.: IJNREC/420/2019). The initial 
recruitment was conducted by the clinical investigator from UMMC and IJN respectively according to inclusion and exclusion criteria of the study. After the clinical investigator grants the informed consent from the patients, they were introduced to the researchers. Patient information sheet was given to the patients once the participants agreed with the participation, they signed an informed consent form. Since some patients were unable to read or write, the instruments were administered orally. The researchers read the questions for the patients and the patients answered orally. In order to maintain the confidentiality of the participants, each administered questionnaire data will be coded as anonymous without identify any particular participants, then the survey data will be kept in secure computer with encrypted password. Whereas the informed consent form sheet and hard copy data such as the questionnaire and demography questionnaires that contain participant information will be kept in locked cabinet under Psychology and Counselling Department, University Pendidikan Sultan Idris, Malaysia. The data will be kept for 7 years before its termination. Only the researchers and ethics reviews board as necessary will have access to the data.

\section{DATA ANALYSIS}

The data was analysed using The R Project for Statistical Computing version 3.6.1. Three analysis were run that are item endorsement index, Cronbach's Alpha and item-total correlation. Item endorsement index was computed in order to examine the level of endorsement of each item by the participants. An index of below .30 will show a low level of endorsement while an index of above .80 will show a high level of endorsement in that particular item.[15] The internal consistency of the SCHFI $v 6.2$ was examined by calculating the Cronbach's alpha coefficient and itemtotal correlation. Hair et al. suggested an acceptable Cronbach's alpha of 60 to .70.[16] Item-total correlation of .30 to .70 is considered acceptable.[17]

\section{RESULTS}

The participants recruited in this study aged between 25 to 88 years. The mean age of the participants was 61.39 (SD = 15.39). Most of the participants were male (60.00\%) and more than half of the participants were married $(72.50 \%)$. Since a large portion of the participants had an older age, most of them were retired or unemployed. The common comorbidities of reported by the participants include hypertension, diabetes mellitus, high cholesterol, kidney failure and cancer. Most of them were diagnosed with heart failure for more than one year. Therefore, they were doing regular appointment to have their medical checkup. On average, the participants spend about three days per year at hospital that is once in four months. Two participants were excluded in calculating the mean and standard deviation for "time spent at hospital" because of the outliers data. The demographic characteristics of the participants were shown in Table 1.

TABLE 1: DEMOGRAPHIC CHARACTERISTICS OF SAMPLES $(\mathrm{N}=80)$

$\begin{array}{lll}\text { CHARACTERISTICS } & \text { NO. } & \% \\ \text { Gender } & & \\ \text { Male } & 48 & 60.00 \\ \text { Female } & 32 & 40.00 \\ \text { Marital Status } & & \\ \text { Single/Widowed/Divorced } & 22 & 27.50 \\ \text { Married } & 58 & 72.50 \\ \text { Education } & & \\ \text { Primary } & 24 & 30.00 \\ \text { Secondary } & 32 & 40.00 \\ \text { Tertiary } & 23 & 28.75 \\ \text { Postgraduate } & 1 & 1.25 \\ \text { Working Status } & & \\ \text { Employed } & 29 & 36.25 \\ \text { Unemployed } & 51 & 63.75 \\ \text { Comorbidity } & & \\ \text { None } & 48 & 60.00\end{array}$




\begin{tabular}{lll}
\hline One & 22 & 27.50 \\
Two & 9 & 11.25 \\
Three & 1 & 1.25 \\
Ejection Fraction (\%) & & \\
Reduced (HFrEF) & 27 & 33.75 \\
Mid-range (HFmEF) & 18 & 22.50 \\
Preserved (HFpEF) & 35 & 43.75 \\
\hline & $\mathrm{M}$ & $\mathrm{SD}$ \\
\hline Age (years) & 61.39 & 15.39 \\
Time Spent at Hospital (days/year) $(\mathrm{n}=78)$ & 3.71 & 3.26 \\
\hline
\end{tabular}

Abbreviation: $M$, mean; SD, standard deviation

\section{ITEM ENDORSEMENT INDEX}

Each item was analysed first to examine the level of endorsement of each self-care behavior by the participants. Table 2 showed the item endorsement index of each item in each subscale in an ascending order. In maintenance subscale, item 6 (Receive a flu shot yearly) showed the lowest level of endorsement (Item difficulty = .30). This meant getting a flu shot was not a regular practice by the participants. Item 3 (eat low salt diet) showed the highest level of endorsement with item endorsement index of .71, showing that most of the participants were having a low salt diet. In management subscale, item 11 (Call your doctor or nurse for guidance) showed a high level of endorsement (Item difficulty $=.91$ ). This showed that calling doctor and nurse for guidance was a common practice among the participants. On the other hand, item 9 (Reduce fluid intake) showed the lowest endorsement with item endorsement index of .68. Lastly, item 14 (Recognize changes in your health if they occur) in confidence subscale showed the lowest confidence level with item endorsement index of .65 while item 18 (Follow the treatment advice you have been given) showed the highest confidence level with item endorsement index of 71. All the items in SHCFI v6.2 Chinese showed an acceptable range of endorsement $(.30-.71)$ except item 11.

TABLE 2: ITEM ENDORSEMENT INDEX OF SCHFI V6.2 CHINESE

\begin{tabular}{ll} 
ITEM & ITEM ENDORSEMENT INDEX \\
\hline Maintenance subscale & \\
Item 6 & .30 \\
Item 1 & .50 \\
Item 2 & .56 \\
Item 5 & .59 \\
Item 4 & .65 \\
Item 3 & .71 \\
\hline Management subscale & \\
Item 9 & .68 \\
Item 7 & .73 \\
Item 10 & .76 \\
Item 8 & .78 \\
Item 12 & .78 \\
Item 11 & .91 \\
\hline
\end{tabular}




\begin{tabular}{ll}
\hline Confidence subscale & \\
Item 14 & .65 \\
Item 13 & .66 \\
Item 15 & .67 \\
Item 16 & .67 \\
Item 17 & .68 \\
Item 18 & .71 \\
\hline
\end{tabular}

Reliability Test of Self-Care of Heart Failure Index (SCHFI) The items were further examined by calculating the Cronbach's Alpha and item-total correlation. The Cronbach's Alpha of maintenance subscale was .52. Deletion of item 6 (Receive a flu shot yearly) would increase the Cronbach's Alpha by 0.04 , whereas deletion of other items would lower it. The item-total correlation for item 1 to 6 ranged between .04 - .63, indicating all items in maintenance subscale were homogeneous except item 6 . For management subscale, the Cronbach's Alpha was .67. Deletion of any item in management subscale did not raise the Cronbach's alpha of the subscale. The item-total correlation of item 7 to 12 was .48 to .67 which was in an acceptable range. Therefore, item 7 to 12 were retained. The Cronbach's Alpha of confidence subscale was .90 . Deletion of any item would lower the Cronbach's alpha of the subscale. The items in confidence subscale were homogeneous because the item-total correlation of all items was greater than .70. Thus, all the items were retained. Item statistics of each subscale was shown in Table 3.

TABLE 3: ITEM STATISTICS OF EACH SUBSCALE IN SCHFI V6.2 CHINESE

\begin{tabular}{lll}
\hline ITEM & $\begin{array}{l}\text { CORRECTED ITEM-TOTAL } \\
\text { CORRELATION }\end{array}$ & $\begin{array}{l}\text { CRONBACH'S ALPHA } \\
\text { IF ITEM DROPPED }\end{array}$ \\
\hline Maintenance subscale & & .49 \\
Item 1 & .39 & .49 \\
Item 2 & .34 & .42 \\
Item 3 & .51 & .49 \\
Item 4 & .36 & .39 \\
Item 5 & .63 & .56 \\
Item 6 & .04 & \\
\hline Management subscale & & .65 \\
Item 7 & .48 & .62 \\
Item 8 & .55 & .65 \\
Item 9 & .48 & .64 \\
Item 10 & .45 & .60 \\
Item 11 & .67 & .61 \\
Item 12 & .58 & .89 \\
\hline Confidence subscale & & .88 \\
Item 13 & .71 & .89 \\
Item 14 & .75 & .87 \\
Item 15 & .71 & .87 \\
Item 16 & .81 & .88 \\
Item 17 & .83 & \\
Item 18 & .80 & \\
\hline
\end{tabular}


The Cronbach's alpha of maintenance subscale was low. However, the Cronbach's alpha of management and confidence subscale were acceptable. This suggested that the management and confidence subscale of SCHFI showed an acceptable internals consistency between items. An internal consistency implied that the items in the subscales were measuring the same construct and reliable to be used to measure the self-care behavior.

\section{DISCUSSION AND CONCLUSION}

Heart failure is a complex clinical disease that require multidisciplinary approaches. Therefore, the patients have to undergo psychometric assessment to ensure optimal clinical outcomes.[18] Self-care Heart Failure Index (SCHFI) v6.2 Chinese is an instrument that can achieve that purpose. Because it covers three aspects of the self-care behavior, that are self-care maintenance, self-care management and self-care confidence. Overall, SCHFI v6.2 Chinese showed an acceptable internal consistency.

However, there are some items that need specific attention. In maintenance subscale, item 6 (Receive a flu shot yearly) showed a lower item endorsement index than in SCHFI v6.2 English. [13] This showed that getting a flu shot as a mean of avoiding sick less common practiced by the participants in this study. The current study was conducted among the Malaysian population whereas the original study was conducted in Western country, thus this item was perceived differently by different population. Besides, item 6 also had the lowest item-total correlation. This showed that item 6 was heterogeneous to the other items in the subscale. Most of the participants did not receive a flu shot yearly. Therefore, it is suggested to drop this item in the SCHFI v6.2 Chinese to be used in Malaysia.

Item 4 (Do some physical activity) showed a low item-total correlation. Most of the patients in this study did not do physical activity to maintain a healthy lifestyle. Since heart failure patients may experience shortness of breath depend on their heart failure severity, they have to get advice from healthcare professional on the type of exercise that is suitable with their health condition.

On the other hand, item 11 (Call your doctor or nurse for guidance) showed a higher level of endorsement than in the SCHFI v6.2 English. [13] It can be concluded that seeking advice from healthcare professionals was a common response to heart failure symptoms by the patients in this study. Item 11 also showed the highest item-total correlation. In line with $\mathrm{Yu}$ et al. who conducted a study using the same instrument, Chinese patients in Hong Kong regard seeking medical help as self-care behavior.[7] However, the authors also found that item 11 did not fit into any factor in SCHFI v6.2 Chinese. Further examination on the factor structure of SCHFI v6.2 Chinese need to be conducted.

All the items in management subscale were found to be homogenous indicating these items were measuring the ability of patients to recognize heart failure symptoms (item 7), implement treatments (item 8-11) and evaluate the effectiveness of treatment (item 12) in line with the definition of self-care management. As for confidence subscale, all the items were found to be homogenous in this study. Looking into each item, it measured the confidence level of the patients in doing self-care maintenance and self-care management. Item 13, 17 and 18 concerned about the confidence level of patients at symptom monitoring and medical adherence (self-care maintenance) while item 14, 15 and 16 measured the confidence level of patients at recognizing symptoms, responding to symptoms and evaluating the effectiveness of treatment (self-care management).

\section{CONCLUSION}

This study has proven the reliability and validity of Self-Care of Heart Failure Index (SCHFI) v6.2 Chinese among Malaysian population. The internal consistency of SHCFI v6.2 Chinese was acceptable and its discriminant validity with WHOQOL-BREF was shown. In Malaysia with a diversity of languages, a Chinese language instrument is important for the use of Chinese patients especially those who cannot communicate in other language except in their mother tongue which is Chinese. In providing a good service in healthcare setting, communication should not be a barrier that could affect the quality of treatment given. Therefore, developing an instrument in the language that can be understood by the patient is the responsibility of healthcare professionals. Healthcare professional can utilize SCHFI Chinese to assess the heart failure patients in order to identify the capability of heart failure patients in performing a proper self-care. This enables the healthcare professional to have more information and understanding about the heart failure patients. Based on the result from the assessment of SCHFI Chinese, healthcare professional can provide appropriate education to the heart failure patients so that they are able to recognize and handle the symptoms of heart failure effectively. Eventually, this 
prevents and lowers the rate of readmission after the patients are discharged.

Since the number of samples in this study was limited, factor analysis cannot be conducted to identify the factor structure of the Self-Care of Heart Failure Index (SCHFI). Additionally, the samples recruited in this study were heart failure patients with ejection fraction ranged from reduced to preserved. The result of this study cannot be generalized to entire heart failure population. In future research, it is recommended to conduct a confirmatory factor analysis with a larger sample size to confirm the three-factor structures of SCHFI.

\section{References}

1. World Health Organization. Cardiovascular diseases (CVDs). 2017. Available: https://www.who.int/newsroom/fact-sheets/detail/cardiovascular-diseases(cvds) (Assessed 12/6/2020)

2. Bernama, Heart disease still leading cause of death for Malaysians. 2019. Available:

https://www.freemalaysiatoday.com/category/nation /2019/01/24/heart-disease-still-leading-cause-ofdeath-for-malaysians/ (Assessed 12/6/2020)

3. National Heart Association of Malaysia. Clinical Practice Guidelines: management of Heart Failure. 4th ed. Kuala Lumpur, Malaysia: National Heart Association of Malaysia; 2019.

4. Reyes EB, Ha JW, Firdaus I, et al. Heart failure across Asia: same healthcare burden but differences in organization of care. Int J Cardiol 2016; 223: 163-167. https://doi.org/10.1016/i.ijcard.2016.07.256.

5. Star2.com. When the heart fails. 2017. Available: https://www.star2.com/health/wellness/2017/08/13/w hen-the-heart-fails (Assessed 12/6/2020)

6. Ahmad Hisham S, Hashim R, Mohamed AL, et al. Knowledge, attitude, self-care practice and healthrelated quality of life (HRQOL) among heart failure patients in a Malaysian tertiary hospital. Am J Pharmacol Sci 2019: 7(1): 18-24. http://doi.org/ 10.12691/ajps-7-1-4.

7. YU DSF, Lee DTS, Thompson DR, et al. Assessing selfcare behaviour of heart failure patients: cross-cultural adaptation of two heart failure self-care instruments. Hong Kong Med J 2010; 16(Sppl 3): 13-16.

8. Riegel B, Lee CS, Dickson VV, et al. An update on the self-care of heart failure index. Eur. J. Cardiovasc.
Nurs. 2009;24(6):485-497.

https://doi.org/10.1097/JCN.0b013e3181b4baa0.

9. Bernama. Malaysians developing heart disease at younger age. 2018. Available:

<https://www.nst.com.my/news/nation/2018/10/41974 9/malaysians-developing-heart-disease-younger-age> (Assessed 12/6/2020)

10. Vimala G, Omar SZ. Interpersonal communication skill barrier faced by cardiology doctors at National Heart Centre Malaysia. Int J Acad Res Bus Soc Sci 2016; 6(6): 355-369. https://doi.org/10.6007/IJARBSS/v6-i6/2202.

11. Mohd Ghazi A, Roslan A, Chew D, et al. Angiotensin receptor neprilysin inhibitor (ARNI) for heart failure with reduced ejection fraction - early clinical experience in Institut Jantung Negara. Int J Cardiol 2017; 249(Sppl): S37. https://doi.org/10.1016/j.ijcard.2017.09.133.

12. Tung HH, Chen SC, Yin WH, et al. Self care behavior in patients with heart failure in Taiwan. Eur J Cardiovasc Nurs 2013; 11 (2): 175-182. http://doi.org/10.1016/j.ejcnurse.2011.02.002.

13. Riegel B, Carlson B, Moser DK, et al. Psychometric testing of the Self-Care of Heart Failure Index. J Card F $2014 ; 10(4): 350-360$. https://doi.org/10.1016/i.cardfail.2003.12.001.

14. Riegel B, Dickson VV, Faulkner KM. The situationspecific theory of heart failure self-care. J Cardiovasc Nurs 2016; 31 (3): 226-235. https://doi.org/10.1097/jen.0000000000000244.

15. Cohen RJ, Swerdlik ME. Psychological testing and assessment: An introduction to tests \& measurement. 9th ed. New York: McGraw-Hill Education; 2018.

16. Hair JF, Black WC, Babin BJ, et al. Multivariate data analysis. 7th ed. London: Pearson Education Limited; 2010.

17. DeVaus D. Surveys in social research (Social Research Today). 6th ed. London: Routledge; 2013.

18. Hisham SA, Hashim R, Roslan WAP, et al. Development \& validation of a bilingual psychometric instrument for assessment of knowledge, attitude, selfcare practice and health-related quality of life (KAPQHF) among heart failure patients. J. Cardiovasc Disease Res 2020; 11 (4): 4-11. https://doi.org/10.31838/jcdr.2020.11.03.29. 